\title{
Porezne reforme u zemljama članicama Europske unije
}

\author{
VJEKOSLAV BRATIĆ Institut za javne financije
}

\begin{abstract}
U vrijeme izuzetno izražene potrebe za konsolidacijom hrvatskih javnih financija i rasprava o promjenama hrvatskog poreznog sustava, na temelju Izvješća Europske komisijer, u tekstu se analiziraju porezne promjene kojima su u 20II. i prvoj polovici 2OI2. članice Europske unije (EU) pokušale konsolidirati svoje javne financije.
\end{abstract}

Zbog financijske i ekonomske krize značajno se pogoršalo stanje javnih financija u većini zemalja članica EU-a, te su u 2OII. i prvoj polovici 2OI2. mijenjale svoje fiskalne politike. U Izvješću Europske komisije iz listopada 20ı2. (u daljnjem tekstu: Izvješće), analiziraju se pokušaji konsolidacije javnih financija, te najnoviji porezni trendovi i promjene u pojedinim članicama. Uočljiv je porast ukupnog poreznog opterećenja (uključujući i doprinose za socijalna osiguranja) i poreznih prihoda, te povećanje postojećih poreza (stopa i/ili osnovica) u mnogim članicama.

\section{PROMJENE U EUROPSKOJ UNIJI}

Iz tablice I. ${ }^{2}$ je vidljivo kako je najveći broj zemalja članica povećavao stope $\mathrm{i} /$ ili osnovice poreza na dohodak, poreza na potrošnju (PDV i trošarine), te doprinosa za socijalna osiguranja.

Porezi na dohodak. U zemljama članicama porezi na dohodak najčešce su mijenjani privremenim povećanjem općih prireza ili doprinosa solidarnosti za visoko dohodovne

\footnotetext{
I European Commission (20I2a).

2 AT-Austrija, BE-Belgija, BG-Bugarska, CY-Cipar, CZ-Češka, DE-Njemačka, DK-Danska, EE-Estonija, EL-Grčka, ES-Španjolska, FI-Finska, FR-Francuska, HU-Mađarska, IE-Irska, IT-Italija, LT-Litva, LU-Luksemburg, LV-Latvija, MT-Malta, NL-Nizozemska, PL-Poljska, PT-Portugal, RO-Rumunjska, SE-Švedska, SI-Slovenija, SK-Slovačka, UK-Velika Britanija.
}

osobe (Belgija, Grčka, Italija, Cipar, Luksemburg, Portugal i Španjolska) te usvajanjem mjera za smanjenje ukupnog poreznog opterećenja, najčešće povećanjem poticaja za rad za posebne skupine. Porez na dohodak time je postao progresivniji, a najviša prosječna stopa blago je porasla s 37,9 na $38,1 \%{ }^{3}$.

Porez na dobit. Velik broj članica mijenjao je osnovicu poreza na dobit (npr. uvođenjem olakšica za investicije u fizički kapital ili istraživanje i razvoj, te ograničavanjem mogućnosti odbitka drugih stavki, npr. operativnih gubitaka). Ujedno je - iako u manjoj mjeri - nastavljen dugoročni trend smanjenja zakonskih i prosječnih stopa (s 23,7 na 23,5\%). Najviše stope mijenjale su samo Velika Britanija, Finska, Slovenija, Grčka i Nizozemska, a neke su članice prirezima ili pristojbama, koje se primjenjuju samo za najveće kompanije, povećale granične porezne stope.

Doprinosi za socijalno osiguranje. Stope su povećane u mnogim članicama, a skromno su ih snizile samo Irska i Njemačka (za mirovinsko osiguranje).

Porez na dodanu vrijednost (PDV). U gotovo otprilike polovici zemalja članica povećane su standardne (prosječno s I9,8 na 2I\%) i/ili snižene stope PDV-a.

Trošarine. U većini članica povećane su zakonske stope, prije svega za okoliš, električnu energiju, alkohol i duhan, a jedino smanjenje (za motorna goriva) dogodilo se u Sloveniji.

3 Uvođenjem dodatnih poreznih razreda sa stopom od $35 \%$ i privremenim naknadama najveći je porast zabilježio Cipar (s 30 na 38,5\%). U Španjolskoj je najviša stopa poreza na dohodak povećana sa 43 na čak $52 \%$. 
Tablica I.

Porezne promjene u zemljama EU-a u 20II. i 20I2. (prva polovica)

\begin{tabular}{|c|c|c|c|}
\hline & & Zakonske stope & Osnovica ili posebni režimi \\
\hline \multirow{2}{*}{$\begin{array}{l}\text { Porez na } \\
\text { dohodak }\end{array}$} & povećanje & $\begin{array}{c}\text { II zemalja } \\
\text { (BE, DK, CY, FI, EL, ES, IE, IT, LU*, NL, PT) }\end{array}$ & $\begin{array}{c}\text { I4 zemalja } \\
\text { (AT, BE, CZ*, DK, ES**, FI, FR, } \\
\text { EL, HU, IE, PL, PT, SK, UK) }\end{array}$ \\
\hline & smanjenje & $\begin{array}{c}4 \text { zemlje } \\
\text { (FI, HU, LV, NL) }\end{array}$ & $\begin{array}{c}\text { I3 zemalja } \\
\text { (CZ, DK, EE, FI, DE, ES, } \\
\text { HU, IE, LV, MT, NL, SE, UK) }\end{array}$ \\
\hline \multirow{2}{*}{$\begin{array}{l}\text { Porez na } \\
\text { dobit }\end{array}$} & povećanje & $\begin{array}{l}2 \text { zemlje } \\
\text { (FR, PT) }\end{array}$ & $\begin{array}{c}6 \text { zemalja } \\
\text { (CZ, AT, BE, DK, ES**, HU) }\end{array}$ \\
\hline & smanjenje & $\begin{array}{c}5 \text { zemalja } \\
\text { (UK, FI, EL, SI, NL) }\end{array}$ & $\begin{array}{c}6 \text { zemalja } \\
\text { (ES, HU, IT, LT, LU, UK) }\end{array}$ \\
\hline \multirow{2}{*}{$\begin{array}{l}\text { Doprinosi } \\
\text { za socijalno } \\
\text { osiguranje }\end{array}$} & povećanje & $\begin{array}{c}\text { IO zemalja } \\
\text { (AT, BG, CY, FR, EL, HU, LV, PL, PT, UK) }\end{array}$ & $\begin{array}{l}2 \text { zemlje } \\
\text { (IE, SK) }\end{array}$ \\
\hline & smanjenje & $\begin{array}{l}2 \text { zemlje } \\
\text { (DE, IE) }\end{array}$ & $\begin{array}{l}\text { I zemlja } \\
\text { (CZ) }\end{array}$ \\
\hline \multirow{2}{*}{$\begin{array}{l}\text { Porez na } \\
\text { dodanu } \\
\text { vrijednost }\end{array}$} & povećanje & $\begin{array}{c}\text { I4 zemalja } \\
\text { (PT, UK, CY, ES**, IE, HU, LV, } \\
\text { PL, SK, IT, FR, BG, EL, CZ) }\end{array}$ & $\begin{array}{c}\text { I2 zemalja } \\
\text { (AT, BE, BG, CY, DK, EL, } \\
\text { ES }^{* *}, \text { FI, LV, NL, PL, PT) }\end{array}$ \\
\hline & smanjenje & - & $\begin{array}{c}6 \text { zemalja } \\
\text { (CY, EL, ES, IE, LT, PL) }\end{array}$ \\
\hline \multirow[t]{2}{*}{ Trošarine } & povećanje & $\begin{array}{c}25 \text { zemalja } \\
\text { (AT, BE, BG, CY, CZ, DE, EL, ES, FI, FR, HU, IE, IT, } \\
\text { LT, LU, LV, MT, NL, PL, PT, RO, SE, SK, SI, UK) }\end{array}$ & $\begin{array}{c}4 \text { zemlje } \\
\text { (DK, EE, LV, PL) }\end{array}$ \\
\hline & smanjenje & $\begin{array}{l}\text { I zemlja } \\
\text { (SI) }\end{array}$ & - \\
\hline \multirow{2}{*}{$\begin{array}{l}\text { Oporezivanje } \\
\text { imovine }\end{array}$} & povećanje & $\begin{array}{c}6 \text { zemalja } \\
\text { (CY, EL, ES, IE, PT, UK) }\end{array}$ & $\begin{array}{c}4 \text { zemlje } \\
\text { (CY, IT, LT, LV) }\end{array}$ \\
\hline & smanjenje & $\begin{array}{l}\text { I zemlja } \\
(\mathrm{NL})\end{array}$ & - \\
\hline
\end{tabular}

* Privremeni porast u $201 \mathrm{I}$.

** Promjene uvedene nakon zadnjeg datuma izrade Izvješća.

Napomene: tablica sadrži i velike, ali privremene porezne promjene, no ne i one manje. Uvođenje novih poreza analizirano je kao povećanje zakonskih stopa, a promjene poreznih razreda (pragova) kao promjena poreznih osnovica. Naknade solidarnosti uvedene su u: BE - za financijski dohodak, CY - za doprinose za socijalno osiguranje, EL i IT - na visoki dohodak, LU - privremeno, dok su u PT i ES ove naknade analizirane kao porast zakonskih stopa. Porez na dohodak: u FI i NL - smanjeno oporezivanje dohotka od rada, a povećano oporezivanje dohotka od kapitala.

Izvor: European Commission (20I2a: 24)

Oporezivanje imovine. Samo je nekoliko članica mijenjalo oporezivanje imovine (povećanjem stopa i proširenjem osnovice) - Grčka, Italija, Latvija, Litva, Portugal i Španjolska. Zbog najavljenog uvođenja poreza na nekretnine od travnja 20I3. u Hrvatskoj, slijedi kratki osvrt na promjene u članicama EU-a:

- Grčka, koja je još 2oio. uvela progresivni porez na nekretnine, uvela je i posebnu naknadu na rezidentnu imovinu, koja se računa na površinu stambene jedinice, uzimajući u obzir njenu starost i lokaciju, a prikuplja se putem računa za električnu struju.

- Italija je ukinula izuzeće za osnovne nekretnine i povećala katastarsku vrijednost nekretnina za $60 \%$.

- Latvija je udvostručila progresivne stope za stambene objekte, te proširila poreznu osnovicu uključivanjem pomoćnih objekata, parkirnih mjesta te kuća i zemljišta $\mathrm{u}$ vlasništvu crkvenih organizacija koje se ne koriste u religijske svrhe.

- Litva je proširila osnovicu, pa se godišnji porez od I\% plaća na vrijednost iznad 290.ooo eura za nepokretnu imovinu u vlasništvu fizičkih osoba koja se ne koristi u komercijalne svrhe (što je ranije bilo izuzeto).

- Portugal je povećao najnižu i najvišu stopu poreza za gradske (urbane) nekretnine za o,I postotni poen.

- Španjolska je u općinskom porezu na nekretnine za 20I2. i 20I3. uvela privremenu naknadu za nepokretnu imovinu s ažuriranom katastarskom vrijednošću iznad prosječne vrijednosti nekretnine u svakoj općini.

\section{STANJE, IZAZOVI I PREPORUKE EUROPSKE UNIJE}

Unatoč svim promjenama, strukturna obilježja poreznog sustava članica i dalje su ostala jednaka, a razlike u udjelima poreza u BDP-u, ukupnom poreznom opterećenju i njegovom sastavu i dalje su jako izražene.

Nakon nekoliko godina uzastopnog pada udjela poreznih prihoda u BDP-u i njegove najniže vrijednosti u 2009., taj udjel je 20Io. stabiliziran na oko 38,4\% ${ }^{4}$.

4 Primjerice, dok je u 20Io. ukupni udio poreza u BDP-u u Litvi iznosio 27,I\%, u Danskoj je iznosio čak 47,6\%. 
No, udio se uvelike razlikuje među članicama i općenito je viši u starim, nego u novim zemljama članicama. Osim toga, očit je dugoročni porast stopa PDV-a i paralelni trend sve nižeg oporezivanja dohotka od rada i kapitala. Takvi su trendovi u skladu s nedavnim istraživanjima koja su potvrdila kako je "PDV jedan od poreznih oblika s najnižim negativnim učincima na gospodarski rast” (više u: European Commission, 2OII). različitih vrsta poreznih izdataka u direktnim porezima, posebice porezu na dobit; poboljšanje kvalitete i učinkovitosti rada poreznih administracija, npr. smanjenjem troškova administriranja poreza i snažnijim oslanjanjem na elektronsko ispunjavanje poreznih obveza, a sve radi smanjenja neslužbene ekonomije, zlouporaba u PDV-u i porezne evazije. Oporezivanje stambenih jedinica često se previše oslanja na periodične poreze za promet (transakcije) na ne-

Tablica 2.

Promjene trošarina u zemljama EU-a u 2OII. 2012.

\begin{tabular}{|c|c|c|c|}
\hline & & Zakonske stope & Osnovica ili posebni režimi \\
\hline \multirow[t]{2}{*}{ Energija i okoliš } & povećanje & $\begin{array}{c}\text { I7 zemalja } \\
\text { (AT, BG, FI, DE, EL, ES, HU, IE, IT, } \\
\text { LV, LT, MT, NL, PT, RO, SK, UK) }\end{array}$ & $\begin{array}{c}4 \text { zemlje } \\
\text { (DK, EE, LV, PL) }\end{array}$ \\
\hline & smanjenje & $\begin{array}{l}\text { I zemlja } \\
\text { SI }\end{array}$ & - \\
\hline \multirow{2}{*}{$\begin{array}{l}\text { Duhan, alkohol, } \\
\text { šećer i dr. }\end{array}$} & povećanje & $\begin{array}{c}\text { 2I zemlja } \\
\text { (AT, BE, CY, CZ, DE, EE, ES, FI, FR, HU, LV, } \\
\text { LT, LU, NL, PL, PT, RO, SE, SK, SI, UK) }\end{array}$ & - \\
\hline & smanjenje & - & - \\
\hline
\end{tabular}

Izvor: European Commission (2012a:29)

Dok većina starih članica prikuplja otprilike gotovo iste iznose prihoda od izravnih i neizravnih poreza te doprinosa za socijalno osiguranje, u novim je članicama udio izravnih u ukupnim porezima niži, jer koriste jednostopni ili proporcionalni porezni sustav 5 .

Postojeće prakse ukazuju na postojanje velikog prostora za povećanje učinkovitosti PDV-a, posebice uporabom raznih izuzeća i sniženih stopa. Izvješće ističe da - što se više bude naglašavala potreba poštivanja načela odredišta - sve će izraženija biti i potreba borbe protiv zlouporaba. To zahtijeva bolju koordinaciju članica i pojednostavnjenje postojećih procedura. Preispituje se i ekonomsko opravdanje sniženih stopa i izuzeća, koja ključno određuju utjecaj sustava oporezivanja dodane vrijednosti na ekonomsku razmjenu pojedine zemlje. Izvješće navodi i kako porezi na potrošnju nisu kvalitetan instrument preraspodjele, snižene stope i izuzeća značajno smanjuju proračunske prihode i povećavaju složenost sustava, što sve utječe i na porast administrativnih i troškova ispunjavanja poreznih obveza.

U Izvješću se analiziraju i predstojeći izazovi i članicama daju preporuke za povećanje efikasnosti poreznih sustava, posebice $u$ vrijeme sporijeg ekonomskog rasta i sve veće potrebe fiskalne konsolidacije. Neke članice mogu koristiti i dodatne mjere: npr. manje oporezivati rad, a više se oslanjati na potrošne, imovinske i ekološke poreze; širenje osnovica, npr. preispitivanjem i/ili ukidanjem

5 U ukupnim porezima, najniži udio izravnih imaju Litva (I7,4\%), Bugarska (I8,8\%), Slovačka (I9,I\%) i Estonija (19,9\%). pokretnu imovinu, te bi članice trebale razmisliti o njihovoj zamjeni porezima na imovinu.

Postojeći instrumenti očuvanja i zaštite okoliša, uključujući i poreze, moraju osigurati ispunjenje tih ciljeva, a porezi na energiju moraju omogućiti dovoljne poticaje za dugoročno smanjenje emisije ispušnih plinova. Članice pri tome mogu koristiti razne mjere za unapređenje postojećeg sustava, kao što su prilagodba poreznih stopa na fosilna goriva prema njihovom ugljičnom i energetskom sastavu, indeksiranje poreza na okoliš, ponovna analiza stopa PDV-a za energiju, smanjenje povlastica za automobile koji se koriste u poslovne svrhe, te oporezivanje vozila prema emisiji $\mathrm{CO} 2$.

\section{PROMJENE U HRVATSKOJ}

I u Hrvatskoj su u 20I2. provedene brojne, a za 20I3. planirane su i dodatne porezne izmjene.

Izuzev smanjenja stope doprinosa za zdravstveno osiguranje, većina je drugih poreznih mjera koncentrirana na snažnije ostvarenje javnih prihoda. Povećava se opća i uvodi snižena stopa PDV-a na određene proizvode i ugostiteljske usluge, ukidaju se stanovita prava odbitka pretporeza i povećava prag za ulazak u sustav PDV-a. U sustavu oporezivanja dobiti proširuje se umanjenje osnovice za iznos ostvarene dobiti kojom se povećava temeljni kapital društva, uvodi se plaćanje poreza po odbitku na dividende i udjele u dobiti koji se inozemnim pravnim osobama isplaćuju po stopi od ı2\%, izuzev u slučaju dividendi. Ujedno se naglašava poboljšanje učinkovitosti naplate poreza i rada porezne uprave, te snažnija porezna disciplina. 
Tablica. 3.

Porezne promjene u Hrvatskoj u 2012. i 2013. (plan)

\begin{tabular}{|c|c|c|c|}
\hline & & $\begin{array}{l}\text { Zakonske } \\
\text { stope }\end{array}$ & Osnovica \\
\hline \multirow{2}{*}{$\begin{array}{l}\text { Porez na } \\
\text { dohodak }\end{array}$} & povećanje & - & $\mathrm{x}$ \\
\hline & smanjenje & $\mathrm{x}$ & - \\
\hline \multirow{2}{*}{$\begin{array}{l}\text { Porez na } \\
\text { dobit }\end{array}$} & povećanje & - & - \\
\hline & smanjenje & - & $\mathrm{x}$ \\
\hline \multirow{2}{*}{$\begin{array}{l}\text { Doprinosi } \\
\text { za socijalno } \\
\text { osiguranje }\end{array}$} & povećanje & - & - \\
\hline & smanjenje & $\mathrm{x}$ & - \\
\hline \multirow{2}{*}{$\begin{array}{l}\text { Porez na } \\
\text { dodanu } \\
\text { vrijednost }\end{array}$} & povećanje & $\mathrm{x}$ & - \\
\hline & smanjenje & - & $\mathrm{x}$ \\
\hline \multirow{2}{*}{ Trošarine } & povećanje & $\mathrm{x}$ & - \\
\hline & smanjenje & $\mathrm{x}$ & - \\
\hline $\begin{array}{l}\text { Oporezivanje } \\
\text { imovine }\end{array}$ & \multicolumn{3}{|c|}{$\begin{array}{l}\text { planira se uvođenje poreza na nekretnine } \\
\text { od I. } 4.2 \text { OI3. }\end{array}$} \\
\hline
\end{tabular}

Napomena: uvođenje novih i usklađivanje postojećih, odnosno ukidanje pojedinih trošarina, analizirano je kao povećanje odnosno smanjenje zakonskih stopa.

\section{LITERATURA}

---, 2012. Designations and abbreviations to use. Dostupno na: <http://publications.europa.eu/code/en/ en-370IOo.htm>.

European Commission, 20II. „Tax reforms in EU: Tax policy challenges for economic growth and fiscal sustainability”. Taxation Papers, Working paper, No. 28. Luxembourg: Office for Official Publications of the European Communities. Dostupno na: 〈http://ec.europa.eu/taxation customs/resources/documents/taxation/gen_info/ economic_analysis/tax_papers/taxation_paper_28_ en.pdf>.

European Commission, 2012a. „Tax reforms in EU Member States, Tax policy challenges for economic growth and fiscal Sustainability 2012 Report”. Taxation Papers, Working paper, No. 34. Luxembourg: Office for Official Publications of the European Communities. Dostupno na: 〈http://ec.europa.eu/taxation_customs/resources/ documents/taxation/gen_info/economic_analysis/ tax_papers/taxation_paper_34_en.pdf .
Sve provedene i predložene porezne promjene u Hrvatskoj manje-više prate najnovija kretanja i preporuke EU-a o potrebi snižavanja poreznog opterećenja rada i povećanja poreza na imovinu i potrošnju. No, otvoreno je pitanje bi li ovakve izmjene uopće bile potrebne da početkom 20oo-tih nije krenula kontinuirana praksa mijenjanja postojećeg poreznog sustava, osobito uvođenjem brojnih olakšica, oslobođenja, povlastica i izuzeća kojima je poremećena konzistentnost, transparentnost, učinkovitost i stabilnost poreznog sustava. Ujedno se, u cilju konsolidacije hrvatskih javnih financija mnogo - osim hvalevrijednog i dobrodošlog smanjenja doprinosa poslodavaca - propušta napraviti na znatno problematičnijoj rashodovnoj strani proračuna. Zbog toga su preporuke koje Institut za javne financije ističe već godinama, aktualne i danas: "Poreznom politikom ne smiju se provoditi mjere socijalne, ekonomske ili razvojne politike nego je njezin osnovni cilj i svrha što jednostavnije, učinkovitije i pravednije prikupljanje poreznih prihoda kojima se trebaju pokrivati postojeći izdaci za javne potrebe. Uostalom, u Hrvatskoj je upravo rashodna strana proračuna problematična i nikakve promjene na prihodnoj strani bez radikalne reforme rashoda ne mogu pridonijeti poboljšanju hrvatskih javnih financija”(Kuliš, 2003).

European Commission, 20I2b. Taxation Trends in the European Union 2012. Luxembourg: Publications Office of the European Union. Dostupno na: $<$ http://epp.eurostat. ec.europa.eu/cache/ITY_OFFPUB/KS-DU-I2-ooI/ EN/KS-DU-I2-OOI-EN.PDF>.

European Commission, 2012c. „European Economic Forecast”. European Economy I, Spring 20I2. European Commission: Directorate-General for Economic and Financial Affairs. Dostupno na: 〈http://ec.europa.eu/economy_ finance/publications/european_economy/2012/ pdf/ee-2OI2-I_en.pdf >.

Kuliš, D., 2003. „Kretanja u hrvatskome poreznom sustavu”. Newsletter, br. I4. Dostupno na: 〈http://www.ijf.hr/ newsletter/I4.pdf>.

PwC, World Bank and IFG, 20II. Paying Taxes 2012 - The Global Picture. Dostupno na: 〈http://www.doingbusiness. org/ /media/FPDKM/Doing\%2OBusiness/Documents/ Special-Reports/Paying-Taxes-2OI2.pdf `.

\begin{tabular}{ccc}
$\begin{array}{c}\text { Mjesečni razredi } \\
\text { od I. ožujka 20I2. (u kn) }\end{array}$ & & Stopa (u \%) \\
\hline do 2.200 & I2 \\
\hline $2.200-8.800$ & 25 \\
\hline iznad 8.800 & 40 \\
\hline
\end{tabular}

DODATAK - DETALJNE POREZNE PROMJENE U HRVATSKOJ U 2OI2. I PLAN PROMJENA U 2013.

\section{Porez na dohodak}

Promjene od I. ožujka 20I2.:

- Osnovni osobni odbitak povećava se s I.80o na 2.200 kn mjesečno, a za mirovine s 3.200 na $3.400 \mathrm{kn}$;

- Stope poreza na dohodak i mjesečni razredi promijenjeni su na sljedeći način: 
- Porez na dohodak po stopi od ı2\% primjenjuje se na primitke od dividendi i udjela u dobiti koji se isplaćuju nakon I. ožujka 2OI2., osim onih ostvarenih do 3I. prosinca 200o., bez obzira kada se isplaćuju. Neoporezivi iznos dividende i udjela u dobiti je 12.000 kn godišnje, ali se priznaje samo na temelju godišnje porezne prijave (obračunava, obustavlja i uplaćuje isplatitelj). I dividende i udjeli u dobiti ostvareni u razdoblju od I. siječnja 200I. do 3I. prosinca 2004. oporezuju se po stopi od I2\%.

- Razlika primitaka u slučaju nedostatne dobiti za pokriće predujma dividende ili udjela u dobiti oporezuje se po stopi od $40 \%$.

- Uvodi se oporezivanje mirovina ostvarenih u inozemstvu. Predujam poreza na dohodak po toj osnovi obračunava i isplaćuje sam porezni obveznik u roku od osam dana od primitka dohotka.

- Uvodi se oporezivanje dodataka na mirovinu.

- Dohotkom od kapitala smatra se razlika isplaćenog predujma dobiti, ako dobit društva nije dostatna za pokriće tog predujma.

- Ukida se obveza vođenja evidencije o obračunatim i isplaćenim dividendama i udjelima u dobiti, te dostavljanje propisanog izvješća Poreznoj upravi.

\section{Porez na dobit}

- Osnovica se umanjuje za iznos ostvarene dobiti kojom se povećava temeljni kapital društva. Prvi put se primjenjuje u postupku podnošenja prijave poreza na dobit za $2 \mathrm{OI} 2$.

- Uvodi se plaćanje poreza po odbitku na dividende i udjele u dobiti koji se od I. ožujka 20I2. isplaćuju inozemnim pravnim osobama po stopi od $12 \%$, osim u slučaju isplata dividendi i udjela u dobiti ostvarenih do 3I. prosinca 2000., bez obzira kada se isplaćuju. No, prvo se postupa prema odredbama Ugovora o izbjegavanju dvostrukog oporezivanja.

- Vrijednosna usklađenja po osnovi ispravka vrijednosti potraživanja kupaca nastala od I. ožujka 20I2. priznaju se kao rashod ako je od dospijeća potraživanja do kraja poreznog razdoblja proteklo više od 60 dana (umjesto dosadašnjeg roka od ı2o dana).

- Prilikom utvrđivanja jesu li poslovni odnosi između povezanih osoba ugovoreni po tržišnim cijenama, ne daje se prednost upotrebi metode usporedivih nekontroliranih cijena.

\section{Porez na dodanu vrijednost}

Promjene od I. ožujka 20I2.:

- Standardna stopa PDV-a podiže se s 23 na $25 \%$.

- Uvodi se snižena stopa PDV-a od Io\% na isporuke jestivih ulja i masti, dječju hranu, isporuku vode (osim vode u bocama ili drugoj ambalaži) i bijeli šećer od trske i šećerne repe.

- Ukida se pravo na povrat pretporeza za nabavu i najam plovila namijenjenih za razonodu, zrakoplova, osobnih automobila i drugih sredstava za osobni prijevoz (uz određene iznimke), te za troškove reprezentacije. Kada se takva dobra kod kojih se nije moglo iskoristiti pravo na povrat pretporeza, biti ce pri isporuci oslobođena plaćanja PDV-a.

Promjene od I. siječnja 20I3.:

- Prag za ulazak u sustav PDV-a podiže se s 85.000 na $230.000 \mathrm{kn}$.

- Snižena stopa PDV-a od Io\% uvodi se na ugostiteljske usluge, izuzev alkoholnih pića, tj. na usluge pripremanja hraneiusluga prehrane, te pripremanjeiusluživanje bezalkoholnih pića i napitaka, vina i piva u ugostiteljskim objektima.

- Prag za tromjesečni obračun PDV-a povećava se s 300.000 na $800.000 \mathrm{kn}$.

- Umjesto nulte stope uvodi se snižena stopa od 5\% za kruh, mlijeko, lijekove i knjige.

- Oporezivanje sniženom stopom od 5\% za plovila za sport i razonodu koja se stavljaju u carinski postupak puštanja u slobodan promet do 3I. svibnja 20I3., a koja su prethodno bila u postupku privremenog uvoza.

Tijekom 2013.

- Najavljuje se smanjenje stope PDV-a za turističke usluge na I0\%.

\section{Obvezni doprinosi}

- Od I. svibnja 20I2. stopa doprinosa za zdravstveno osiguranje smanjena je s I5 na I3\%.

\section{Trošarine}

- Od I. siječnja 20I3. ukidaju se trošarine na luksuzna dobra.

- Od I. srpnja 20I3. novi obračun trošarina na automobile prema emisiji CO2 i vrijednosti (električni, hibridni i automobili s nižom potrošnjom i emisijom $\mathrm{CO} 2$ bit će manje, a skuplji i snažniji automobili više oporezovani). Ukidaju se trošarine za stare automobile.

- Usklađivanje trošarina na cigarete i alkohol prema minimalnim EU stopama.

- Uvođenje trošarina na sve ostale oblike energije (električna energija, plin i loživo ulje).

- Razmatra se i mogućnost uvođenja viših trošarina na bezalkoholna pića koja imaju više šećera i umjetnih sastojaka.

\section{Porez na nekretnine}

- Od I. travnja 20I3. planira se uvesti porez na nekretnine. 